\title{
Potential tsunamigenic faults of the 2011 off the Pacific coast of Tohoku Earthquake
}

\author{
Takeshi Tsuji ${ }^{1}$, Yoshihiro Ito $^{2}$, Motoyuki Kido $^{2}$, Yukihito Osada ${ }^{2}$, Hiromi Fujimoto ${ }^{2}$, \\ Juichiro Ashi $^{3}$, Masataka Kinoshita ${ }^{4}$, and Toshifumi Matsuoka ${ }^{1}$ \\ ${ }^{1}$ Graduate School of Engineering, Kyoto University, C1-1-110 Kyotodaigaku-Katsura, Nishikyoku, Kyoto 615-8540, Japan \\ ${ }^{2}$ Graduate School of Science, Tohoku University, 6-6 Aramaki-aza-aoba, Aoba-ku, Sendai, Miyagi 981-8578, Japan \\ ${ }^{3}$ Atmosphere and Ocean Research Institute, the University of Tokyo, 5-1-5 Kashiwanoha, Kashiwa-shi, Chiba 277-8564, Japan \\ ${ }^{4}$ Institute for Research on Earth Evolution (IFREE), Japan Agency for Marine-Earth Science and Technology (JAMSTEC), \\ 2-5 Natsushima-cho, Yokosuka-shi, Kanagawa 237-0061, Japan
}

(Received April 13, 2011; Revised May 19, 2011; Accepted May 20, 2011; Online published September 27, 2011)

\begin{abstract}
Faults related to the tsunamigenic 2011 Tohoku-Oki Earthquake $\left(M_{\mathrm{w}} 9.0\right)$ were investigated by using multichannel seismic reflection data acquired in 1999 and submersible seafloor observations from 2008. The location of the fault system interpreted in the seismic reflection profile is distributed around the area with largest slip and tsunami induction of the 2011 event. Cold-seep communities along the trace of the branch reverse fault and a high scarp associated with the trace of a normal fault suggest current activity on these faults. We interpret the fault system in the seismic profile as a shallow extension of the seismogenic fault that may have contributed to the resulting huge tsunami.
\end{abstract}

Key words: 2011 Tohoku-Oki Earthquake, tsunamigenic faults, seismic reflection data, seafloor observation, cold-seep communities, high scarp.

\section{Introduction}

The 11 March 2011 earthquake $\left(M_{\mathrm{w}} 9.0\right)$ ruptured a wide area along the plate interface off the Pacific coast of Tohoku, Japan (Japan Meteorological Agency JMA, 2011; Yagi, 2011; Fig. 1(a)). The northwestern margin of the Pacific plate is subducting beneath the northeastern Japan Arc at a convergence rate of $8.6 \mathrm{~cm} / \mathrm{yr}$ (DeMets et al., 1990) and frequently generates interplate earthquakes and tsunamis (e.g., Yamanaka and Kikuchi, 2004). However, the tsunami caused by this earthquake was extremely huge, and observations with an ocean bottom pressure gauge revealed short-period spike-shaped sea surface uplift (e.g., Fujii et al., 2011). In order to reveal mechanisms of the impulsive tsunami generation, shallow fault distributions and geometries are important.

Here, we identify a series of faults from a seismic reflection profile obtained in 1999 near the hypocenter (JMA, 2011) and seafloor observations of the fault trace made in 2008 by the manned submersible Shinkai 6500. Because the surveyed area includes the region where the largest vertical displacement is predicted to have occurred (Ueno and Satake, 2011; Shao et al., 2011; Fig. 1(a)), the shallow faults here are likely to be directly related to the tsunami characteristics.

Copyright (c) The Society of Geomagnetism and Earth, Planetary and Space Sciences (SGEPSS); The Seismological Society of Japan; The Volcanological Society of Japan; The Geodetic Society of Japan; The Japanese Society for Planetary Sciences; TERRAPUB.

doi:10.5047/eps.2011.05.028

\section{Seismic Reflection Data}

Multi-channel seismic reflection data acquired by $R / V$ Kairei (JAMSTEC) in 1999 (Line MY102 of KR99-08 cruise; Tsuru et al., 2002) were analyzed for an investigation of fault geometry and to select dive points for seafloor observations (Fig. 1(b)). In the seismic survey, the sound source was an array of $\sim 200$-L (12,000 cubic inch) airguns fired every $50 \mathrm{~m}$. The receiver array was a 156-channel, 4-km streamer, and the record length was $13.5 \mathrm{~s}$.

We applied conventional seismic processing, including trace editing, multiple suppression, deconvolution, velocity analysis, stacking, and post-stack migration (Yilmaz, 2001). We then obtained the depth-domain profile (Fig. 2) by using stacking velocity. Due to the limitation of the streamer length, it was difficult to determine seismic velocities accurately in the deeper lithology.

\section{Geological Interpretation}

On the reflection profile (Fig. 2), we identified three predominant faults branching from the plate boundary fault: (A) a backstop reverse fault acting as a boundary between a seaward accreted sequence and a landward less-deformed Cretaceous sequence (von Huene et al., 1994; Tsuru et al., 2002), (B) a branch reverse fault constructing the significant seafloor slope break (Fig. 2(d)), and (C) a steeply dipping normal fault branching from a plate boundary fault and extending towards a seafloor ridge (Fig. 2(c)). However, potential underplating structures are observed landward of the backstop reverse fault defined by Tsuru et al. (2002) (Fig. 2(b)).

Displacement along the steeply-dipping normal fault has 

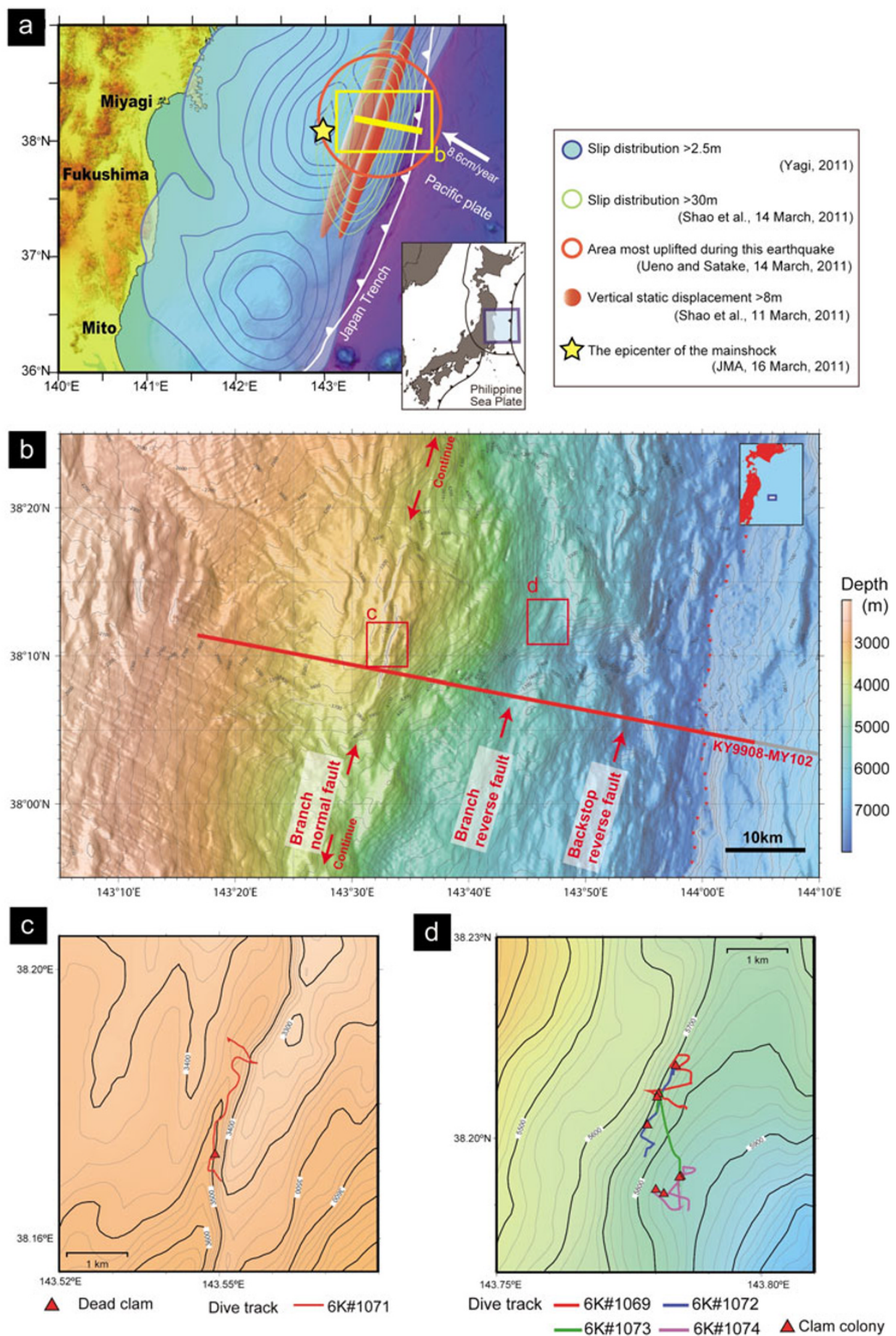

Fig. 1. (a) Seismic survey line (yellow line), energy and slip distribution of the 2011 earthquake, and area of tsunami induction. Yellow rectangle indicates the area of panel (b). (b) Bathymetric map around the seismic survey line (red line) (Sasaki, 2004). Reverse triangles indicate the location of a landward margin of the trench. We identify the ridge associated with steeply dipping normal fault and the seafloor slope break associated with branch reverse faults. Red rectangles indicate the areas of panels (c) and (d). (c) Dive track at the seafloor ridge (Dive \#1071). Red triangle indicates the location where a dead clam was observed. (d) Dive tracks at the seafloor trace of the branch reverse fault (Dive \#1069, \#1072, \#1073, and \#1074). Red triangles indicate the locations of clam colonies.

offset a Cretaceous sequence surface by $\sim 800 \mathrm{~m}$ (Fig. 2(c)). The plate boundary fault and steep normal fault appear to bound a pop-up structure. The seafloor ridge associated with the normal fault displacement is well identified on the seafloor topography (Fig. 1(b)) and is as long as several tens of kilometres parallel to the trench axis. Therefore, the normal fault should play an important role in the plate convergent margin off Miyagi.

\section{Submersible Seafloor Observations}

In May 2008, we used the manned submersible Shinkai 6500 (YK08-06) to visit two points along this seismic line: the seafloor trace of the (B) branch reverse fault (Fig. 2(d)) and a ridge associated with displacement along the $(\mathrm{C})$ 

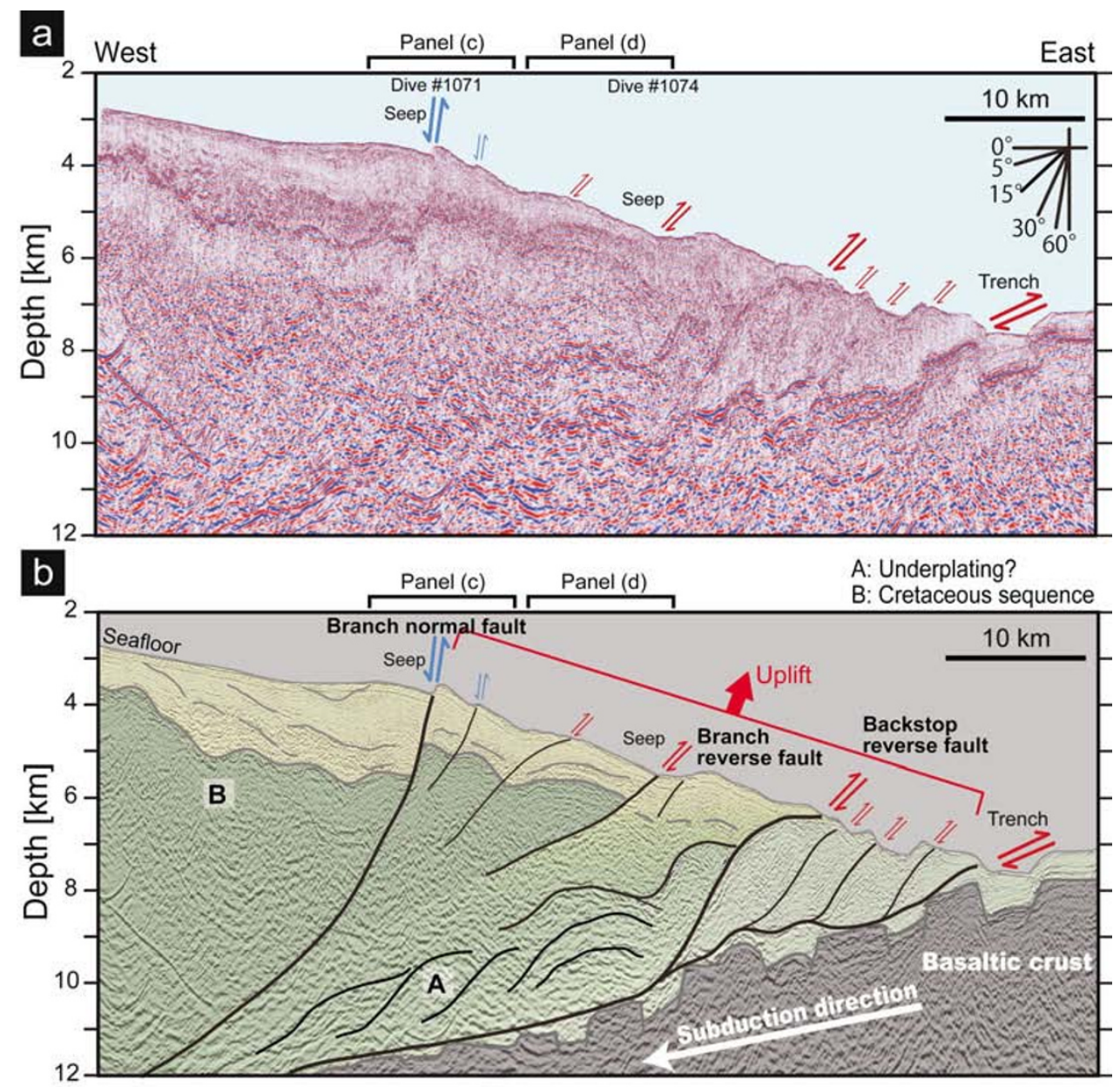

C

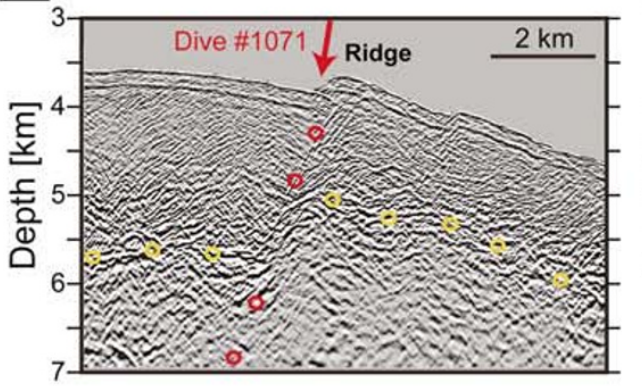

d

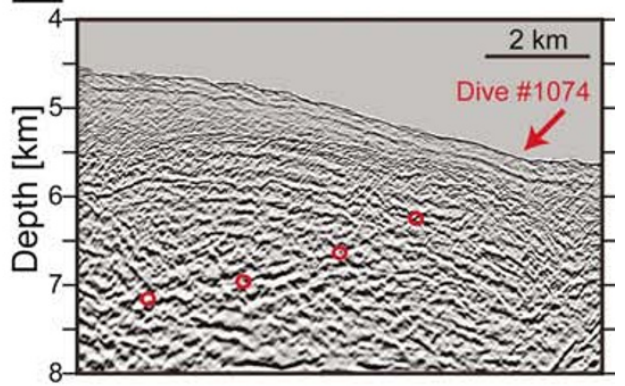

Fig. 2. (a) Original seismic reflection profile with amplitude gain control (AGC). (b) Composite seismic reflection profile with geological interpretations. (c) Detailed profile around the normal fault and ridge structure. Displacement of steeply dipping fault (red dots) offsets the sediment basement surface (yellow dots). (d) Detailed profile around the seafloor trace of branch reverse fault (red dots). The fault can be identified as a clear reflection.

branch normal fault (Fig. 2(c)). Because of an insufficient depth capability of Shinkai 6500, we could not dive to the seafloor trace of the (A) backstop reverse fault located at a depth of $\sim 7000 \mathrm{~m}$ as well as plate boundary fault ( 7500 m).

Chemosynthetic communities observed along the branch reverse fault trace (Figs. 1(d), 2(d), 3(a)) indicate that fluid passes through open fractures along the fault plane. Similar cold seeps on the seafloor traces of active faults in the northern Japan Trench (Ogawa et al., 1996) and other convergent margins (Toki et al., 2004) suggest that the interpreted faults on the off-Tohoku seismic profile are also active.

A scarp $\sim 150 \mathrm{~m}$ high marks the trace of the normal fault (Figs. 1(c), 2(c), 3(b)), and continuously exists along the ridge ( $\sim 2 \mathrm{~km}$ dive track of the Shinkai). The slope angle of the scarp is nearly vertical and overhanging in places (Fig. 3(b)). We sampled rocks from the steep scarp and estimated the depositional age as $0.51-0.85 \mathrm{Ma}$ from both calcareous nannofossils (e.g., Okada and Bukry, 1980) and fossil diatoms (e.g., Yanagisawa and Akiba, 1998). Because there is a fresh scarp surface without any manganese coating and because we observed a dead clam there, this scarp may have been generated by recent earthquake activity.

\section{Summary and Discussions}

Faults related to the tsunamigenic 2011 Tohoku Earthquake were investigated by using seismic reflection data and submersible seafloor observations. The fault system identi- 

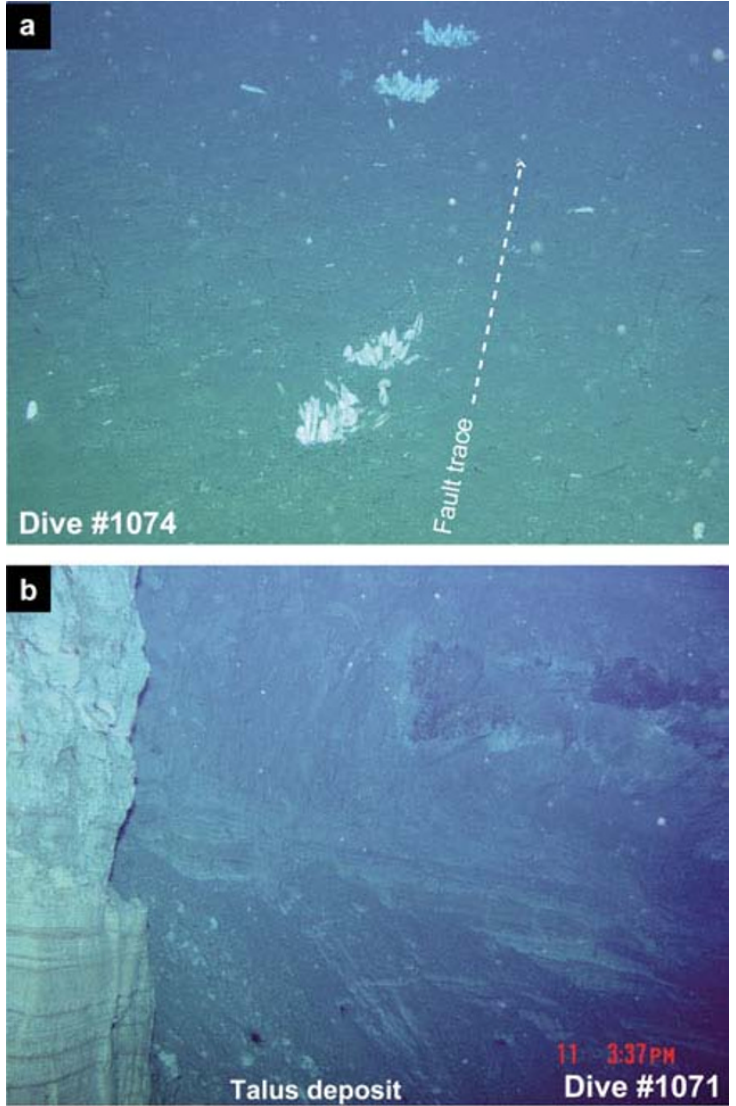

Fig. 3. (a) Chemosynthetic biological communities observed along the seafloor trace of the branch reverse fault (Fig. 2(d)). (b) Still video image (view from north) of the scarp attributed to the displacement of a steeply dipping normal fault (Fig. 2(c)). A fresh surface without manganese coating suggests recent activity of the normal fault.

fied in this study is located at the seaward edge of the rupture area (Yagi, 2011) or consistent with the maximum rupture area (JMA, 2011; Shao et al., 2011) (Fig. 1(a)). The largest tsunami was inferred to have been induced near the interpreted fault (Ueno and Satake, 2011) where the largest vertical static displacement is expected (Shao et al., 2011). Therefore, the interpreted fault system may be shallow extensions of the seismogenic fault that also slipped during the earthquake.

Seafloor displacement during the earthquake estimated by the Japan Agency for Marine-Earth Science and Technology (JAMSTEC, 2011) demonstrated that the seafloor between the trench and the normal fault is significantly deformed in a seaward direction (50 m horizontal displacement) and uplifted (7 m vertical displacement). Therefore, the normal fault seems to act as a landward boundary of a significant displacement region. This observation suggests that the geological unit between the normal fault and the plate boundary fault should be uplifted (moves to seaward direction), as inferred from the fault interpretations on seismic profile (Fig. 2(b)).

Because displacement along the plate boundary fault near the trench is much larger than the deeper fault landward of our survey area (e.g., Fujii et al., 2011), the geological unit above the plate boundary fault is in a tensile state of stress. Due to the tensile stress state, the normal faults should be ruptured during this earthquake event.

If the steeply-dipping normal faults slipped during the earthquake, in addition to the plate boundary fault, they can induce the huge tsunami even as a result of a smaller displacement. The potential underplating unit landward of the backstop reverse fault may also have caused uplift that contributed to the tsunami.

Acknowledgments. We thank T. Sasaki (University of Tokyo) for the bathymetric map. We are grateful to two reviewers for their useful comments. The bathymetric data in Fig. 1(b) were acquired by $R / V$ Kairei, Yokosuka, and Mirai (JAMSTEC). The seismic data were acquired by $R / V$ Kairei (JAMSTEC). This study is supported by Grant-in-Aid for Scientific Research on Innovative Areas (21107003).

\section{References}

DeMets, C., R. G. Gordon, D. F. Argus, and S. Stein, Current plate motions, Geophys. J. Int., 101, 425-478, 1990.

Fujii, Y., K. Satake, S. Sakai, M. Shinohara, and T. Kanazawa, Tsunami source of the 2011 off the Pacific coast of Tohoku, Japan earthquake, Japan Geoscience Union meeting 2011, MIS036-P116, 2011.

Japan Agency for Marine-Earth Science and Technology (JAMSTEC), Seafloor deformation around the hypocenter associated with the 2011 off the Pacific coast of Tohoku, Japan earthquake (available at http://www.jamstec.go.jp/j/about/press_release/20110428/), 2011

Japan Meteorological Agency (JMA), The 2011 off the Pacific coast of Tohoku Earthquake-Portal-, on 16 March, 2011, (available at http://www.jma.go.jp/jma/en/2011_Earthquake.html), 2011.

Okada, H. and D. Bukry, Supplementary modification and introduction of code numbers to the low latitude coccolith biostratigraphic zonation, Marine Micropaleontol, 5, 321-325, 1980.

Ogawa, Y., K. Fujikura, Y. Iwabuchi, Y. Kaiho, N. Izumi, A. Inoue, Y. Nogi, K. Taira, T. Kikuma, I. T. Lee, K. Kodera, S. Nagai, H. Okano, A. Ikegami, K. Fujioka, and T. Kuwano, Dive report of "Shinkai 6500" 1995 cruise at the northern Japan Trench landward slope (Dives 272-277)—Geomorphology, geology and biology of the Sanriku Escarpment-, JAMSTEC J. Deep Sea Res., 12, 1-22, 1996.

Sasaki, T., Subduction tectonics in the northern Japan Trench based on seafloor swath mapping bathymetry, $\mathrm{PhD}$ thesis, the University of Tokyo, 2004.

Shao, G., X. Li, C. Ji, and T. Maeda, Preliminary Result of the Mar 11, 2011 Mw 9.1 Honshu Earthquake, on 11 March and 14 March, 2011, (available at http://www.geol.ucsb.edu/ faculty/ji/big_earthquakes/2011/03/0311/Honshu.html), 2011.

Toki, T., U. Tsunogai, T. Gamo, S. Kuramoto, and J. Ashi, Detection of low-chloride fluids beneath a cold seep field on the Nankai accretioanary wedge off Kumano, south of Japan, Earth Planet. Sci. Lett., 228, 37-47, 2004.

Tsuru, T., J.-O. Park, S. Miura, S. Kodaira, Y. Kido, and T. Hayashi, Along-arc structural variation of the plate boundary at the Japan Trench margin: Implication of interplate coupling, J. Geophys. Res., 107, 2357, doi:10.1029/2001JB001664, 2002.

Ueno, T. and K. Satake, Inverse refraction diagram of Tsunami, on 14 March, 2011, (available at http://outreach.eri.u-tokyo.ac.jp/eqvolc/ 201103_tohoku/eng/\#inverse), 2011.

von Huene, R., D. Klaeschen, and B. Cropp, Tectonic structure across the accretionary and erosional parts of the Japan Trench margin, J. Geophys. Res., 99(B11), 22,349-22,361, 1994.

Yagi, Y., Fault rupture process (Version 3), (available at http://www.geol.tsukuba.ac.jp/ yagi-y/EQ/Tohoku/), 2011.

Yamanaka, Y. and M. Kikuchi, Asperity map along the subduction zone in northeastern Japan inferred from regional seismic data, J. Geophys. Res., 109, B07307, doi:10.1029/2003JB002683, 2004.

Yanagisawa, Y. and F. Akiba, Refined Neogene diatom biostratigraphy for the northwest Pacific around Japan, with an introduction of code numbers for selected diatom biohorizons, J. Geol. Soc. Jpn., 104, 395 414, 1998.

Yilmaz, O., Seismic data analysis, Society of Exploration Geophysicists, Tulsa, OK, 2001.

T. Tsuji (e-mail: tsuji@earth.kumst.kyoto-u.ac.jp), Y. Ito, M. Kido, Y. Osada, H. Fujimoto, J. Ashi, M. Kinoshita, and T. Matsuoka 